\title{
Promoting Engaged Scholars: Matching Tenure Policy and Scholarly Practice
}

\author{
Katherine Lambert-Pennington
}

\begin{abstract}
This article explores what an uneven embrace of community engagement means for faculty as they apply for tenure and promotion. It closely examines how three faculty members (including the author) from different departments framed and discussed their engaged scholarly contributions in the presence or absence of departmental guidelines on engaged scholarship. Their experiences and success reveal the influence of departmental context on decisions to include engagement in faculty evaluation criteria and the importance of finding strategies to mitigate the absence or underdevelopment of guidelines.
\end{abstract}

\section{Introduction}

Over the past twenty years, many colleges and universities have embraced community engagement as a key element of their institutional mission and culture. This move represents a shift from an isolated ivory tower model of teaching and research to a connected model of knowledge dissemination through various forms of scholarship and public service (Boyer, 1996; Lynton, 1995). Becoming an engaged institution is a process of transforming how universities relate to their respective communities (Saltmarsh, Giles, et al., 2009; Holland \& Gelmon, 1998) and how they view key roles of faculty-research, teaching and service (Fitzgerald et al., 2012; Bringle \& Hatcher, 2000; Holland, 1997). Incorporating community engagement into tenure and promotion criteria is a tangible way to strengthen the institutional culture of engagement and encourage faculty and student involvement in engaged research and learning activities (O'Meara \& Braskamp, 2005; Holland, 1997, 2005; O’Meara, 2005). While such changes are key to aligning institutional rhetoric and practice (Moore \& Ward, 2010), the processual and often bureaucratic nature of policy changes often take time to trickle down to the departmental level, resulting in an uneven embrace of community engagement across departments.

This article explores what an uneven embrace of engagement means for faculty as they apply for tenure and promotion. In the first section, I consider the history and process of incorporating engaged scholarship into University of Memphis tenure and promotion policies and the degree to which engaged scholarship been incorporated into departmental guidelines. Findings suggest that while departmental adoption of guidelines for engaged scholarship runs the gamut from explicit to minimal to none, a number of community-engaged faculty have successfully been tenured and promoted. Within this context, I closely examine how three faculty members (including the author) in the College of Arts and Sciences successfully utilized engaged scholarship in framing and discussing their scholarly contributions. Their experiences reveal the influence of departmental context on decisions to include engagement in faculty evaluation criteria and the importance of finding strategies to mitigate the absence or underdevelopment of guidelines.

\section{Adjusting Tenure and Promotion Policies}

The University of Memphis began its evolution as a community engaged institution in the early 2000s, under the leadership of President Shirley Raines, who encouraged faculty to build partnerships to support the University's mission as a metropolitan serving university (Cox, 2010). During this period, a group of faculty representing departments and colleges across the University worked with the Provost to establish a University-wide Engaged Scholarship Award and revise the University's Tenure and Promotion policies

Copyright @ 2016 Metropolitan Universities Vol. 27 No. 2 (Summer 2016), 50-58, DOI: 10.18060/21126 
to include engaged scholarship. Revisions to University-wide policies resulted in engaged scholarship subsuming the scholarship of application. It was described as:

Add[ing] to existing knowledge in the process of applying intellectual expertise to collaborative problem-solving with urban, regional, state, national and/or global communities and results in a written work shared with others in the discipline or field of study. Engaged scholarship conceptualizes "community groups" as all those outside of academe and requires shared authority at all stages of the research process from defining the research problem, choosing theoretical and methodological approaches, conducting the research, developing the final product(s), to participating in peer evaluation. Departments should refine the definition as appropriate for their disciplines and incorporate evaluation guidelines in departmental tenure and promotion criteria (University of Memphis Faculty Handbook, 2006).

My analysis of departmental tenure and promotion guidelines reveals that twenty-three departments across six colleges and schools have explicitly incorporated engaged scholarship into their tenure and promotion guidelines. Within the College of Arts and Sciences seven of nineteen departments/programs identify, define, and include criteria for engaged scholarship under scholarship/research. Of the thirteen remaining departments, two retained the language for the scholarship of application and the remaining eleven refer to community outreach under guidelines for service. These policy changes, or lack thereof, form a continuum of incorporation from explicit to minimal to no mention of engaged scholarship.

While the revised guidelines make an important distinction in mode and approach to doing researchcommunity-oriented, collaborative in nature, and sharing authority (O'Meara \& Rice, 2005) - they also clearly maintain the applied scholarly goal of using intellectual expertise to solve practical problems. Thus, the uneven recognition and adoption of engaged scholarship at the departmental level may result from confusion over the difference between applied and engaged scholarship. Or it may reflect varied disciplinary practice with regard to research methodologies. Many of the departments that have incorporated engaged scholarship are professional and applied programs, like Earth Sciences, Anthropology, and Social Work. Additionally, if departments did not have faculty pursuing an engaged scholarly agenda, they may have not seen the need to revise their guidelines to reflect the unique challenges, products, and time involved in doing engaged scholarship. Consequently, as the three case studies below attest, some faculty pushed for and benefitted from revised guidelines, while others found themselves applying for tenure without clear departmental criteria for recognizing and evaluating their community engaged activities.

\section{Building a Case for Engaged Scholarship One Dossier at a Time}

In the cases below, I examine how three faculty members navigated departmental guidelines with different levels of inclusion and specificity with regard to engaged scholarship to build successful tenure and promotion dossiers (two promoted to Associate Professor and one promoted to Full Professor). For each case, I describe the overall departmental context, including tenure and promotion guidelines, and then draw on candidates' written research, teaching, and service narratives (with their permission) to discuss how the candidate describes his/her engaged scholarship practice and documents the impact of his/her work.

Case One: Explicit Guidelines - Department of Anthropology (Assistant to Associate, 2013). The Department of Anthropology has a national reputation as an applied anthropology program and over the last decade has hired faculty with the expectation that they would broaden their research interests to include local, community based research projects. When the candidate in this case (the author) was hired in 2007, senior faculty, who were also active on the University's Engaged Scholarship Committee, explained the applied focus of the department in terms of engaged scholarship. By the beginning of her 
second year, the candidate was involved in two community-based projects: one in partnership with a senior faculty member in City and Regional Planning and the other led by a departmental colleague that had been hired at the same time. The two junior faculty members recognized the tensions inherent in doing engaged scholarship: the tenure clock versus the time involved in building trusting, reciprocal partnerships; and the expectations of peer-reviewed publications versus highly localized reports for community partners. Consequently, prior to mid-tenure review, junior faculty members requested clarification on how engaged scholarship would be evaluated in light of guidelines that primarily defined scholarship and research in terms of the scholarship of application and evaluated it on the basis of receipt of grant/contracts, peer reviewed journal articles, and participation in professional meetings. The resulting conversations highlighted the need to update the guidelines to better reflect the range of scholarship being undertaken by faculty members.

The faculty made three key revisions. First, language was added to link the University's mission as a metropolitan serving institution and its commitment to community engagement to the department's mission to produce scholarship "that seeks to serve its urban, regional, state, national, and global communities" (Anthropology, 2009, 2) Carnegie Foundation and University of Memphis definitions of community engagement and engaged scholarship were designated as attachments to the guidelines. Second, citing Barker's taxonomy (2004), an explanation of engaged scholarship as consisting of "research, teaching, integration and application scholarship that incorporates reciprocal practices of civic engagement into the production of knowledge" was added to the section on Evaluation of Research and Scholarship (Anthropology, 2009, 6). Third, and relatedly, a list of products was added to the criteria for evaluating the scope of a candidate's scholarship:

f. The cluster of products that come out of sustained community engagement, which could include, videos, exhibits, events, GIS maps, websites, and/or reports. The department may draw upon one or more national standards in evaluating engaged scholarship (e.g., National Review Board for the Scholarship of Engagement). (Anthropology, 2009, 7).

Additionally, language was added to encourage candidates to provide evidence of the impact of engaged scholarship, including media coverage, letters from community members, and/or policy change.

The candidate in Case One drew on several elements of the revised guidelines, particularly those related to various types of research products and impact of research, as well as demonstrated links between her research, teaching, and service roles. Her research narrative describes a mix of traditional and engaged scholarship; early funded research and peer-reviewed publications were related to her dissertation, while later projects and publications grew out of local collaborations. In discussing her engaged work, the candidate carefully describes the process behind each engaged scholarly project, including the methods employed (participatory action research) and the roles of community partners, other faculty, and students in shaping and carrying out the research. The candidate returns to student involvement in her teaching narratives, where she describes her pedagogical approach to service learning, the ways community partners and projects are connected to her classes and the products that result from those interactions (e.g. neighborhood social service directory, map of cultural assets in the community).

Beyond the research projects, the research narrative also details the "constellation of products" that resulted from engaged research, including traditional peer-reviewed journals, book chapters, and funded grant proposals, as well as policy documents, community reports, and mobile workshops. As evidence of a peer-review process for community reports and policy documents, the narratives highlight their public dissemination through presentations to local professional organizations and the Memphis City Council, availability on community partner websites, and at community meetings. The research narrative also describes the impact of these projects, citing local news stories, recognition from local and federal agencies, like The White House Office of Faith-based and Community Partnerships, tangible changes that 
resulted from the research (supported by letters from community partners), and awards that the projects or the faculty member received. Finally, the candidate's service narrative links her outreach to regional and national networks created through engaged scholarship projects and research interests.

For the candidate in Case One, the incorporation of engaged scholarship into departmental guidelines was important from both a structural and cultural standpoint. The process of revising the guidelines codified departmental support for engaged scholarly activities and brought policies in line with faculty practice. Additionally, it helped clarify what and how the work would be recognized. Importantly, she was also able to exchange ideas and share experiences with her fellow junior colleague. Outside of the department, the candidate's research partner, who was an experienced engaged scholar, actively mentored her, helping her to chart a pathway and timeline for moving non-traditional products to peer-reviewed publications, and identify possible publication outlets.

Case 2: Minimal Guidelines - Department of City and Regional Planning (Assistant to Associate, 2011). In the early 2000s the Department of City and Regional Planning (CRP) was largely a grant/contract funded technical assistance and research center with a long-standing graduate program. Over the course of the decade, CRP transitioned from a culture of technical assistance to a culture of engagement. This change was prompted by several separate, but reinforcing, dynamics. CRP became part of a newly formed School of Urban Affairs and Public Policy (SUAPP). Faculty revised tenure and promotion guidelines in 2003 to reflect the department's renewed academic mission. Additionally, the retirement of a long-time faculty member created the opportunity to hire a junior faculty member (the candidate in this case) that could enhance the academic profile of the department. With the new hire, the Dean changed faculty contracts from 12 to 9 -months, which aligned with the academic calendar and the practice within the College. Finally, the department hired a new chair (in 2008) that was well known for promoting engaged scholarship at his previous institutions. While these dynamics suggest the emerging importance of engaged scholarship the department, the guidelines in effect when the candidate went up for tenure in 2010 outlined two primary forms of research: disciplinary research, "which is characterized by an aim to advance knowledge in the particular scholarly concerns of the planning profession," and policy research, also labeled as scholarship of engagement, which is "characterized by an aim to provide information and analysis immediately useful to policy-makers in dealing with development problems of urban and regional areas" (City and Regional Planning, 2003, 6). The former encompasses the scholarship of inquiry, integration, teaching, and creative activity and evidence includes (in order of importance) peerreviewed publications, papers published in conference proceeding, and papers and presentations at professional meetings, and innovative course designs disseminated through other venues and technical reports. The latter encompasses the scholarship of application and evidence includes (in order of importance) peer-reviewed products such as planning reports or contracts and non-peer reviewed products that are widely disseminated, technical assistance, and evaluation (City and Regional Planning, 2003, 7).

The candidate's tenure and promotion narratives reflect department's process of transitioning from a contract and technical assistance orientation to an academic community-engaged approach. His early scholarship focused on disciplinary research published in peer-reviewed journals and edited volumes, and the pursuit of contracts and grants to conduct policy related research. The candidate completed most of this work solo, which was the department's customary practice of "expert for hire." Since engaged scholarship was not elaborated in departmental guidelines, the candidate identifies engaged scholarship as a third area of research activity. He aligns his embrace of engaged scholarship with the University's mission statement and its Community Engagement Classification by the Carnegie Foundation. He also underscores the mutually beneficial nature of engaged scholarship and the importance of student involvement. The latter allows him to link engaged scholarship with the three faculty roles.

The research narrative lays out the methodology, rationale, significance of each engaged scholarly project to the discipline and the department, noting relevant products throughout. These include traditional 
products such as grants, peer-reviewed publications, conference presentations, and other publicly disseminated products such as reports, mobile workshops, and appearances on local news media. The service narrative links key departmental service and community outreach activities to community-based research projects and teaching. For example, in his role as supervisor of a Geographical Information Systems (GIS) lab, the candidate was able to extend its use beyond the University through a youth in planning project. Area teenagers were trained on hand-held GIS devices and created interactive maps and blogs using the GIS lab. His teaching narrative describes how curricular and pedagogical changes connected student learning with engaged research projects and community partners over the course of several semesters. For example, students in a class focused on the role of creativity and arts in community development drafted a concept paper on using music and musicians as a tool for community building. The relationships and knowledge the candidate built with community organizations during the class led to a formal collaboration, grant funding, additional courses working on the project, as well as publications and national recognition.

Although engaged scholarship was only minimally part of the department's tenure and promotion guidelines, the candidate developed a research agenda and reputation as an engaged scholar over the course of his time as assistant professor. The impact of his work on Memphis was emphasized in letters from community partners that described both tangible (additional grant funding) and intangible (a deeper sense of community and publicity for the neighborhood) benefits of their relationship. Additionally, the candidate received mentoring and support from the Head of SUAPP, who envisioned the School as an important point of connection between the University and the community, as well as the department chair, who put together an external review committee well versed in engaged scholarship.

Case Three: No mention of engaged scholarship - Department of Psychology (Associate to Full, 2014). Hired in 2006 to lead and administer a center for research on gender and inequality, the candidate in Case Three had a joint appointment in Psychology and Women's Studies.

The candidate's primary duties as the director of the center were to bring together interdisciplinary teams of faculty to address community identified research needs and work with community partners to secure funding to undertake the research. The Dean strongly supported the center's collaborative approach to research and its partnerships with local and regional community organizations and government agencies. As a teacher, the candidate initially taught courses in the Women's Studies Program, but began teaching gender focused courses in the Psychology Department when Women's Studies was dissolved. The candidate applied for promotion to full professor in the Department of Psychology, which has strong focus in clinical psychology and externally funded applied research in education and learning, gambling, language, and trauma. Departmental tenure and promotion guidelines (Department of Psychology, 2010) reflect a traditional research, publication, and grant orientation and do not mention engaged scholarship. Detailed descriptions of criteria for and evidence of faculty activities include peer-reviewed journal publications of an empirical and conceptual nature and grant activity, especially awarded grants and Primary Investigator (PI) designation. The candidate was concerned that her portfolio of work, particularly in the context of the mission and goals of the center, did not conform to the Psychology Department's expectations. With urging from the candidate, the Dean recommended that her tenure and promotion committee be interdisciplinary to reflect the nature of the center; it included faculty from anthropology, public health, and public administration. Additionally, a committee from Psychology reviewed her case. Prior to submitting her dossier, the candidate sought out examples from faculty at the University of Memphis and elsewhere, including the narratives discussed in Cases One and Two, and received guidance from her research collaborators who were Full Professors.

Engaged scholarship provided a way for the candidate to frame her work both within the context of the center and the Department of Psychology and demonstrate an integrated program of research, teaching, and service. Her narratives carefully navigate the seemingly disparate expectations posed by her role as a center director and the Psychology Department's tenure and promotion guidelines. She begins by 
contextualizing the center's mission within the College of Arts and Sciences and the University, with an emphasis on the University's role as a metropolitan serving research institution committed to interdisciplinary and engaged scholarship and its Carnegie Foundation designation as Community Engaged. The candidate then links her approach to working collaboratively with the community to promote interdisciplinary empirical approaches to understanding social inequalities and advocating for change with her shift from an applied psychology approach to engaged scholarship. She specifies this change as one that emphasizes collaborative research and problem solving with community and regional impacts, rather than theory driven research.

The candidate's research program summary identifies three intersecting strands of research, describing the focus, application(s), and research projects that support each strand and publications. Her specific research program descriptions identify key collaborators and agency interlocutors, the roles they played in helping to frame the research questions and methodology, and the interventions that resulted from the collaboration. The descriptions also reveal a balance of peer reviewed articles, external grants, conference presentations, publically disseminated reports and policy impacts, as well as recognition by a national disciplinary association, and almost continual grant funding. The candidate's service narrative further elucidates her reputation and the impact of her work, focusing on the leadership positions she has held on a national advisory board, a national disciplinary association, a national public health agency, as well as with local and state government agencies and non-profits. While the candidate's teaching narratives demonstrate academic and intellectual links to the center and to her research program, her description of her work with graduate students from diverse disciplines is explicitly linked to several of her communitybased research projects.

The candidate's dossier provides ample evidence of engaged scholarship as practice; from collaborative research development based on community partner needs to training students in community based participatory research to wide dissemination of knowledge. Supporting documentation included letters from community partners that spoke to the depth of their relationship to the candidate (and the center) and the importance of their work together to the programs and policies that affect them. An additional form of support came from strategically chosen external reviewers that could evaluate the many facets of the candidate's work, including engaged scholarship.

These three cases share important characteristics, many of which are best practices noted by Jordan, et al. (2009). First, the candidates represented departments or centers with missions that aligned with the purpose and values promoted by engaged scholarship. Second, each candidate's narratives demonstrated the integration of engaged scholarship across their research, teaching, and service roles. Third, their scholarly productivity covered a cross-section of scholarly-peer-reviewed articles, reports, and funded grants. Moreover, in two of the three cases, the collaborative nature of engaged scholarship was key to explaining the significance of interdisciplinary research and publications. Finally, all of the candidates had assurances from departmental and/or college leaders that the University valued engaged scholarship.

\section{Conclusion: Do Tenure and Promotion Policies make a difference?}

While the cases presented here suggest that it is possible to be awarded tenure and promotion as an engaged scholar under a range of departmental policies, going up for tenure in a department without clear criteria for evaluating engaged scholarship remains a risky proposition. Candidates risk not being able to effectively demonstrate the significance of their work, particularly in cases where departments do not value interdisciplinary publications or service learning. Likewise, review committees may not be able adequately distinguish between applied and engaged scholarship or assign appropriate value to the various written and creative products that can result. While choosing external reviewers with engaged scholarship expertise can mitigate this, guidelines have to allow for the possibility that a reviewers might 
come from outside of the discipline. As the number of faculty seeking to do engaged scholarship grows, departments that have yet to incorporate community engagement into their guidelines will need to do so. Insistencies in tenure and promotion policies related to community engagement are evidence of the growing pains associated with becoming an engaged institution. It will take effort on all sides, from pretenure faculty actively advocating for incorporation revision to departmental policies as well as encouragement from Provosts and Deans, to ensure that university policies, structures, and practices are mutually reinforcing.

\section{Acknowledgements}

Many thanks to Joy Clay, Tom Nenon, Ann Harbor, David Cox, and Ruthbeth Finerman for their insights into the history of changes to tenure and promotion process at the University and to Charlie Santo, Lynda Sagrestano, Keri Brondo, and Kenneth Reardon for sharing their experiences as engaged scholars. 


\section{References}

Anthropology Department Tenure and Promotion Guidelines. (2009). Retrieved from http://www.memphis.edu/aa/resources/facres/tenurepromotion/docs/guidelines/anthropology.pdf.

Barker, D. (2004). The scholarship of engagement: A taxonomy of five emerging practices. Journal of Higher Education Outreach and Engagement 9 (2), 123-137.

Boyer, E. (1996). The scholarship of engagement. Journal of Public Service and Outreach 1 (1), 11-20. doi: http://dx.doi.org/10.2307/3824459

Bringle, R. G., \& Hatcher, J. A. (2000). Institutionalization of service learning in higher education. Journal of Higher Education 71 (3), 273-290. doi: http://dx.doi.org/10.2307/2649291

City and Regional Planning Tenure and Promotion Guidelines. (2003). Retrieved from http://www.memphis.edu/aa/resources/facres/tenurepromotion/docs/guidelines/city_planning.pdf.

Cox, D. (2010). History of the scholarship of engagement movement. In H.E. Fitzgerald, C. Burack, \& S. Seifer (Eds.) Handbook of engaged scholarship: Contemporary landscapes, future directions (Vol. 1: Institutional Change, pp. 25-38). East Lansing, MI: Michigan State University Press.

Department of Psychology Tenure and Promotion Guidelines. (2010). Retrieved from http://www.memphis.edu/aa/resources/facres/tenurepromotion/.

Fitzgerald, H., Bruns, K., Sonka, S. T., Furco, A., \& Swanson, L. (2012). The centrality of engagement in higher education. Journal of Higher Education Outreach and Engagement 16 (3), 7-27.

Holland, B. (1997). Analyzing institutional commitment to service: A model of key organizational factors. Michigan Journal of Community Service Learning 4 (1), 30-41.

Holland, B. \& Gelmon, S.B. (1998). The state of the "engaged campus": What have we learned about building and sustaining university-community partnerships? AAHE bulletin 51 (2), 3-6.

Jordan, C. M., Wong, K. A., Jungnickel, P. W., Joosten, Y. A., Leugers, R. C., \& Shields, S. L. (2009). The Community-engaged scholarship review, promotion, and tenure package: A Guide for faculty and committee members. Metropolitan Universities 20 (2), 66-86.

Lynton, E. A. (1995). Making the case for professional service. Forum on faculty roles \& rewards. Washington, DC: American Association for Higher Education.

Moore, T., \& Ward, K. (2010 Fall). Institutionalizing Faculty Engagement through Research, Teaching, and Service at Research Universities. Michigan Journal of Community Service Learning 17 (1), 44-58.

O'Meara, K. A., \& Braskamp, L. (2005). Aligning faculty reward systems and development to promote faculty and student growth. Journal of Student Affairs Research and Practice 42 (2), 369-386. doi: http://dx.doi.org/10.2202/1949-6605.1474

O'Meara, K. A., and Rice, R. E. (2005). Faculty priorities reconsidered: Rewarding multiple forms of scholarship. New York, NY: Jossey-Bass Inc Pub. 
O’Meara K. A. (2005 August). Encouraging multiple forms of scholarship in faculty reward systems: Does it make a difference? Research in Higher Education 46 (5), 479-510. doi:

http://dx.doi.org/10.1007/s11162-005-3362-6

Saltmarsh, D., Giles, Jr., D. E., Ward, E., \& Buglione, S. (2009). Rewarding community-engaged scholarship. New Directions for Higher Education 2009 (147), 25-35. doi:

http://dx.doi.org/10.1002/he.355

\section{Author Information}

Katherine Lambert-Pennington is an Associate Professor of Anthropology whose teaching, research, and community engagement focuses on identity, social inequality, power, community building, and social justice in Australia and the United States. She has helped co-lead several interdisciplinary efforts to support engaged scholarship at the University of Memphis, including the Urban Transformation Initiative and the Strengthening Communities Initiative. She currently serves as the Co-Chair of the University's Engaged Scholarship Committee.

Katherine Lambert-Pennington

Department of Anthropology

University of Memphis

316 Manning Hall

Memphis, TN 38152

Email: almbrtpn@memphis.edu

Telephone: 901-678-2080

Fax: 901-678- 2069 